Natural History in the Field.

WiLl you allow me to draw the attention of students of field botany, field naturalists, and those interested in encouraging natural history in the field, especially schoolmasters who may be initiating classes for the study of our native plants, to the high probability of the present year being quite an exceptionally prolific year for all our sun-loving vegetable flora.

The want of sunshine last year kept all our wild flowers back. Nothing had its full development : flowers were late, foliage was thin, colours were dull and undefined, fruit small and without flavour, seeds unripe.

But one season's loss is the next season's gain ; in all probability the plants this year will be exceptionally fine, and many plants that are usually small and poor will flourish with unusual vigour, while, not improbably, many plants which seldom show themselves here will this year blossom and become visible.

On this account it might be well to advise the starting of classes for the study this year of field natural history, for students, particularly young students, are encouraged to go on with a pursuit that has been very successful at its commencement. Chigwell. W. LINTON WILSON.

\section{Detonating Meteor.}

AcCORDING to the Jamaica Weather Report for November r888, a very brilliant meteor was seen at Kingston, Jamaica, on the evening of November 10 , at $8 \mathrm{~h}$. $52 \mathrm{~m}$. local mean time.

It appeared about $30^{\circ}$ above the south-west horizon, crossed the heavens, and disappeared about $30^{\circ}$ above the north-northeast horizon; and as Kingston is in lat. $18^{\circ} \mathrm{N}$., we have for the point of appearance the celestial co-ordinates R.A. $2 \mathrm{Ih} .24 \mathrm{~m}$. N.P.D. $113^{\circ}$, and for the point of disappearance, R.A. $3^{\mathrm{h}}$. $45 \mathrm{~m}$., N.P.D. $25^{\circ}$.

Mr. R. Johnstone writes:--." It was by far the brightest meteor I have ever seen, and it so lit up the sky as to cause consternation among many of the negro population. Exactly four minutes afterwards I heard a sound as of a distant explosion, which was not quite so loud as the 9 o'clock gun at Port Royal, heard in due time about four minutes later. The sound was heard by other people in Kingston."

As Kingston is $5 \mathrm{~h} .7 \mathrm{~m}$. W. of Greenwich, the meteor appeared November II, Ih. $59 \mathrm{~m}$. a.m. Greenwich civil time; and therefore the meteor falls within the period November II-I 5 , which is one of the large-meteor periods, according to the useful summary given in Whitaker's Almanac.

The interval of four minutes between the appearance of the meteor and the sound of its explosion corresponds to a distance of forty-eight miles. I am sorry that the details are at present incomplete in many respects, but inquiry will be made.

I2 Hartington Road, Ealing, February 2. Maxweli. Hall.

\section{MEMORIAL TO G. S. OHM.}

A MEETING was held on Thursday afternoon, January $3 \mathrm{I}$, in the meeting-room of the Royal Society, the Right Hon. Lord Rayleigh, Sec.R.S., in the chair, for the purpose of promoting the co-operation of English men of science and others in a project, set afoot in the first instance by some of the Professors and other leading men in Munich, of erecting in that city a statue of George Simon Ohm-a man who, although he discovered no new phenomena of very striking importance, yet by the accuracy of his thought, and the clearness of his insight into the true bearings of physical facts, was able to lay one of the principal and firmest parts of the foundation of the noble edifice of modern physics.

The occasion for the proposal at this particular time to erect a memorial to $\mathrm{Ohm}$ is the near approach of the hundredth anniversary of his birth, on March 16, 1789. There are, moreover, reasons why this proposal should be, and no doubt will be, taken up warmly in this country. English physicists may recall with satisfaction that the award of the Copley Medal by the Royal Society on November 30, 1841 , was the first public or official recognition that Ohm received of the value of his work upon the laws of the electric circuit, and that this award contributed in a very great degree to obtain for his researches the attention and appreciation they deserved. It may not be without interest at the present time to refer to the words in which the Chairman, Sir J. W. Lubbock, Bart, V.P. and Treas., announced the award. The following is from the report of the proceedings at the anniversary meeting of I84I :-

"The Council has awarded the Copley Medal for the present year to Dr. G. S. Ohm, of Nuremberg, for his researches into the laws of electric currents, contained in various memoirs published in Schweigger's Journal, Poggendorff's Annalen, and also in a separate work, entitled 'Die galvanische Kette mathematisch bearbeitet,' published at Berlin in the year 1827. In these works, Dr. Ohm has established, for the first time, the laws of the electric circuit; a subject of vast importance, and hitherto involved in the greatest uncertainty. He has shown that the usual vague distinctions of intensity and quantity have no foundation, and that all the explanations derived from these considerations are utterly erroneous. $\mathrm{He}$ has demonstrated, both theoretically and experimentally, that the action of a circuit is equal to the sum of the electromotive forces divided by the sum of the resistances; and that whatever be the nature of the current, whether voltaic or thermo-electric, if this quotient be equal, the effect is the same. He has also shown the means of determining with accuracy the values of the separate resistances and electromotive forces in the circuit. The light which these investigations have thrown on the theory of current electricity is very considerable; and although the labours of $\mathrm{Ohm}$ were for more than ten years neglected (Fechner being the only author who, within that time, admitted and confirmed his views), within the last five years, Gauss, Lenz, Jacobi, Poggendorff, Henry, and many other eminent philosophers, have acknowledged the great value of his researches, and their obligations to him in conducting their own investigations. Had the works of Ohm been earlier known, and their value recognized, the industry of experimentalists would have been better rewarded. In this country those who have had most experience in researches in which voltaic agency is concerned, have borne the strongest testimony to the assistance they have derived from this source, and to the invariable accuracy with which the observed phenomena have corresponded with the theory of Ohm. This accordance it may be observed is altogether independent of the particular hypothesis which may be adopted as to the origin of electromotive force; and obtains equally, whether that force is regarded as being derived from the contact of dissimilar metals, or as referable to chemical agency."

Ohm's book, "Die galvanische Kette," referred to in the above extract, was translated into English by Dr. William Francis, and published in I84I, in the second volume of "Taylor's Scientific Memoirs." The publication of Wheatstone's paper (read to the Royal Society, June I5, r843), entitled "An Account of several New Instruments and Processes for determining the Constants of a Voltaic Circuit," also contributed in an important degree to attract attention to Ohm's work and to cause its importance to be recognized. We may call to mind also that it was in this country that the necessity of expressing electrical quantities in absolute measure first came to be generally recognized, and that the term "ohmad" or "ohm," suggested by Sir Charles Bright and Mr. Latimer Clark at the meeting of the British Association in Manchester, in $186 \mathrm{I}$, first came into use as the name of a decimal multiple of the absolute unit of resistance convenient for practical purposes. Twenty years later, at the Congress of Electricians in Paris, in $188 \mathrm{I}$, the "ohm" was unanimously adopted as an international standard. The name of the modest German Professor has thus come to be an understood term in the language of every civilized community in connection with the conception which he 